\title{
Systematic Dimensional Exploration and Constructional Path of Construction System in Colleges and Universities
}

\author{
Dandan Tong $^{1 *}$, Zhongwei Kang ${ }^{2}$ \\ ${ }^{1}$ College of Animal Science and Veterinary Medicine, Heilongjiang Bayi Agricultural University, 5 \\ xinfeng road, Daqing, China. \\ ${ }^{2}$ General Administration Office, Heilongjiang Bayi Agricultural University, 5 Xinfeng road, Daqing, \\ China.
}

Keywords: University; Study Style; System construction

\begin{abstract}
The style of study is the embodiment of the school's academic spirit, attitude and principle, the style of being a man and the embodiment of the school's temperament and soul. Grasp the essence of the style of study, avoid the misunderstanding of the construction of the style of study, based on the practice of the school in which the author is located, and build a systematic style of study construction system in eight aspects, such as guarantee, guidance, support, supervision, cooperation, support, guidance service and value orientation, so as to accomplish the fundamental task of building people by virtue in colleges and universities.
\end{abstract}

\section{Introduction}

The style of study is the comprehensive embodiment of the school's academic spirit, attitude and principle, the foundation and premise of forming a good school spirit, and the key to cultivate high-quality talents. The style of study, is the style of reading, is the style of learning, but also the style of being a man, a good style of study is a kind of imperceptible huge and invisible spiritual force, is a school temperament and soul. The construction of the work system of good style of study creates an excellent educational environment for college students to grow up and become talented, promotes the overall improvement of students' comprehensive quality, completes the fundamental task of building people by virtue, and helps the cultivation of the pillars of society.

\section{The Essence and Purpose Analysis of Study Style}

\subsection{The Essence of the Style of Study in University}

The style of study in a university is the manifestation of students' learning state, but also the externalization of university idea, university spirit, university culture, university character and university ideal. The essence of its construction is the display of university idea, the manifestation of humanistic spirit and the generation of human life and life meaning [1]. The main body of the construction of university style of study is students, and the entrance of its construction is how to 
fundamentally stimulate students' learning motivation and how to create a good learning atmosphere.

\subsection{The External and Internal Features of the Style of Study}

Learning style as an explicit "ethos" performance includes: learning consciousness, learning initiative, learning emotional fullness, learning drive, learning perseverance, learning attitude, learning interest, learning as well as learning popularity and so on. Learning style as an intrinsic "thought method" mainly refers to the unity of theory with practice, theory and practice, is the most essential and core connotation of learning style [2].

\subsection{The Goal of Learning Style Construction}

Student construction is to solve the problem of organic combination of "teaching" and "learning", advocate teachers' teaching atmosphere of "seeking truth and pragmatism, rigorous study, meticulous teaching and selfless dedication", cultivate students' learning atmosphere of "honesty and trustworthiness, mutual help and mutual love, diligence and studious, hard work and innovation ", and form the academic atmosphere of" unity and cooperation, pursuit of truth, indifference to fame and wealth, advocating morality".

\section{Misunderstanding in the Construction of Study Style}

\subsection{The Style of Study Just is the Misunderstanding of Students' Learning Style}

It is necessary to realize that the construction of the style of study not only includes the explicit content of the style of study, but also requires teachers to teach and educate people, managers to manage and educate people, all teaching staff to serve and educate people, and strive to create a good environment and atmosphere conducive to improving students' comprehensive quality, promoting students' all-round development and cultivating students' interest in learning [3].

\subsection{The Construction of Style of Study is Only the Work of Political Counselors}

The construction of style of study is an important work of ideological and political counselors, and the daily management, activity development, ideological education, award evaluation and evaluation, career planning, employment guidance and other work are closely related to the construction of style of study. What can not be ignored is that a good style of study depends on a good educational environment and needs a comprehensive embodiment of all-round and multi-angle education. The ideological and political education system and teaching management, logistics service system are the main body of the construction of the style of study [4].

\subsection{The Construction of sStudy Style nNeeds Strict Education}

The traditional concept of education is changing quietly. Education is a kind of service product with public nature. Students receiving education become consumers who enjoy educational services. Education should combine management with service, adapt to the development of the times, avoid continuous passive education, and strive to form an interactive education mechanism to achieve the best results of education. 


\subsection{The Effect of Learning Style Construction Oonly Needs Classroom Atmosphere or Learning Achievement Eevaluation}

The essence analysis of the style of study shows the strong connotation of the style of study, classroom discipline, examination results can't become the absolute representative of the evaluation of the style of study, otherwise it will make the construction of the style of study tend to utilitarian, technical, resulting in students' behavior impetuous, quick success and short-term effect, its effectiveness needs a performance, discipline, practice, scientific research, social services, apartment culture, humanistic literacy and other multi-observation evaluation system [4].

\section{Construction of the Word System of Study}

The construction of the style of study adheres to the ideology that education is the first priority, guided by scientific development, and based on the principle of "student-oriented, harmonious development ", thinking deeply, focusing on all-round aspects, grasping the key points, finding a breakthrough point, adhere to systematic and long-term, promoting students' all-round development, constantly improving the quality of education in colleges and universities, and giving full play to the role of building up morality and creating people.

\subsection{System Reform, Institution Construction and Theoretical Research Constitute the Guarantee System of Learning Style Construction}

Strengthening the system construction is an important content to promote the administration of schools according to law. The concept of "running schools according to law" requires that the construction of university system should be strictly based on the principles and regulations of educational law, improve the democratic management system of schools on the basis of straightening out the relationship between the government and schools according to law, and implement the autonomy of running schools. The construction of style of study involves many aspects of school management, such as teaching operation, academic evaluation, academic management, scholarship evaluation, first-best collective selection and so on. System construction is the premise and guarantee, while "system reform" is the dynamic process of promoting the development of style of study. Theoretical research is not only the method of summing up the results, the way to promote the results to play a more effective role, the means to improve the thinking and quality of workers, but also the essential embodiment of a good style of study. The idea and implementation of theoretical research is the booster of the benign operation of the construction of the style of study.

\subsection{Commendation, Publicity and Scientific Research Constitute the Learning Style Construction Guidance System}

Recognition of excellence, set a model, encourage students to take this as a new starting point, set new goals, draw up new plans, to achieve new achievements and hard work, fully play the role of example guide. Recognition content should be closely related to the style of study, the form can be special or annual recognition conference. The special recognition meeting is relatively easy to hold, and can be carried out in combination with reports or deeds, such as learning model soldiers, scientific research competitions, the construction of "learning" student organizations, the advanced deeds of outstanding students in the postgraduate examination, and the report meeting of advanced teams in social practice, etc. The annual commendation meeting is for the recognition of individuals and collectives who have displayed outstanding performance in various aspects such as "morality, 
intelligence, body, beauty and labor" in the past year, the combination of tradition and characteristic awards, the combination of on-site display and multimedia display, rich in content and form, its attraction and influence; publicity is an important part of the organization's ideological and political work, propaganda is power, brand and image [5] Creating a good atmosphere is not only the content but also the goal of the construction of the style of study, and the propaganda work is the necessary means and powerful measure to create the atmosphere. Scientific research is the necessary content to train professionals in colleges and universities. Vigorously commending, guiding the whole process, attaching importance to scientific research, enriching activities, combining propaganda boards, group work, special journals and multimedia multi-channel efforts to publicize, play an exemplary role in guiding learning, and create a good learning model, strive to create an excellent atmosphere.

\subsection{Teaching Style, Class Style and Examination Style Constitute the Supporting System of Study Sstyle Construction}

In the construction of teaching style, class style and examination style, it fully embodies the situation of cooperation and progress between teaching and students' work, strict teaching style, strict class style of study and work, and cooperation between teaching and study work. Teachers are encouraged to lead the construction of style of study, improve the quality of teaching, form a good style of teaching, stimulate and cultivate students' interest in learning through the construction of teachers' ethics and style of study, teaching management, scientific research promotion and academic atmosphere construction, etc. For example, well-known scholars at home and abroad come to school to give lectures, organize international conferences, implement teacher academic reporting system, teaching display and competition, and promote students to re-learn from teacher actions; class, as a complex of beliefs, values and attitudes shared by all or some members, is of great significance to the formation of a good style of study. Class style construction is embodied in class culture cultivation, such as class slogan, class song, class training, class emblem, class style, class mascot determination, class management convention, publicity system, class committee selection and appointment method and responsibility system establishment, class love fund, class mutual aid group establishment, online communication platform construction. Teachers treat the invigilating work seriously and fairly, concentrate on training and guidance before each examination, summarize after the examination, feedback the problems that appear in the invigilating examination, and achieve clear rewards and penalties. Class teachers in each class meeting should focus on the test style and safety issues, imperceptibly affect and educate students. The competent departments draw up the outline of educational tips before examination according to the situation of different periods, and implement the inspection and defense system of counselors' examination rooms. Moderate implementation of integrity examination room activities, that is, no one invigilated examination room, purify the examination room environment, establish a relationship of mutual trust between teachers and students, open a window to show a good style of study [5].

\subsection{Teachers, Class Teachers and Managers Constitute the Supervision System of Learning Style Construction}

Teachers focus on the classroom, the "teacher classroom management manual" not only shows the teacher's duties in the classroom, but also highlights the important role of teachers in the construction of style of study; class teachers focus on the day-to-day, record students' daily situation in the "class teacher work manual", when dealing with class affairs, understand students' ideological dynamics; counselors pay attention to management and service, according to teachers, class teachers, class attendance, student activities and student cadres feedback to grasp the focus of 
students to commend, manage and service. Teachers, class teachers and managers have the key division of labor and cooperation, such as the student academic early warning mechanism implemented by the three parties, in which they play the role of supporting learning, communication and education management, showing the function of joint management of the supervision system [6].

\subsection{School, Parents and Society Constitute a Collaborative System of Learning Style Construction}

As the main position of college students' education, in the period of complex situation at home and abroad and rapid students' ideological dynamics, the school realizes that simple school education or attention can no longer meet the requirements of students and adapt to the changes of form, so it is necessary to actively explore the channels of education and management of students with parents and social forces. From the implementation of the system of home visits by counselors, the formulation of a communication program with parents of new students, the issuance of campus contact cards to parents, the persistence of a letter to parents every semester, the regular updating of parents' information, the invitation to parents to attend the opening ceremony and graduation ceremony, the establishment of new media platforms such as parent interactive WeChat, QQ group, etc., to form a more complete communication mode of communication with parents to educate students in cooperation with parents; Holding literary and corporate celebrity forums, setting up enterprise quality funds, scholarships and joint training courses, carrying out social practice projects, social voluntary service for college students and public welfare activities, aiming to obtain social forces to jointly train college students, and also to make students realize that society pays attention to them and to promote the formation of correct learning attitude and good habits.

\subsection{Care, Attention and Care Constitute the Supporting System of Learning Style Construction}

From the point of view of the construction of style of study, the system of "three levels of support" reflects the main position of students from the aspects of humanistic care and humanized service. The content of the system is: to care for students who are demoted and punished in violation of discipline, to pay attention to students with incorrect classroom attendance and learning attitude, and to care for students with introverted personality and poor learning. Students are kind and the most emotional, the teacher's sincere concern for them, despite our slightly nagging, they will also feel warm, thinking or accepting our advice. In the face of demotion and violation of discipline students, class teachers and counselors teachers do not carry out severe criticism, but care about their development and growth, together with them to sum up early learning results, help to formulate career plans, study plans, and even deal with life problems, ease these students' low mood, and prevent the formation of inferiority complex. The three-level conversation system of class teachers, counselors and college leaders is a comprehensive embodiment of the three-level assistance system, that is, the class teacher communicates with each student at least once a semester. The professional counselors begin to talk with six special groups, such as psychological disorder, economic poverty, learning disorder, physical defect, internet obsession and confusion.

\subsection{Career Planning, Employment Guidance, Entrepreneurship Education Constitute the Guiding Service System of Style of Study Construction.}

Since the 18th National Congress of the Communist Party of China, a number of service policies have been introduced every year. The policy orientation has shifted from paying attention to 
employment rate to paying attention to students' employ ability, employment quality and employment service. Colleges and universities carry out the whole process education in stages, the first grade focuses on career planning guidance, the second grade focuses on entrepreneurship education, the third grade focuses on employment guidance services, and the fourth grade carries out individualized guidance services according to the individual development needs of students. Form the whole process employment ability promotion work system, constitute the style of study construction guidance service system.

\subsection{Nourishing, Exemplary and Compulsory Three Paths Constitute the Leading System of Students' Values}

Student behavior is the result of externalization of values, and learning behavior patterns are influenced by the values of this group. The current network, self-media, cultural soft power has played an important role in the formation of college students' values, taking the education of socialist core values as loyalty, and constructing the value leading system under the background of the times through the three paths of nourishment, demonstration and compulsion [7]. In the nourishing path, we can pay attention to the construction of campus cultural facilities, the creation of cultural works, the ideological and political curriculum, etc. In the demonstration path, we can pay attention to the teacher's personality demonstration, the party member's vanguard leading, the peer's typical demonstration, etc. In the compulsory path, we can pay attention to the construction of governance system, system construction and implementation.

\section{References}

[1] Qiufang L. (2008) Connotation, Essence and Misunderstanding of University Style of Study. Journal of Beijing. Youth Institute of Political Science, 52-56.

[2] Building a style of study. http://baike.sogou.com/v63398182.htm.

[3] Guofeng J. (2003) Misunderstanding and Improvement Measures in the Construction of Study Style in Colleges and Universities. Forum for Higher Education, 147-149.

[4] Shengqiang Y., Qinghua L., Ya Z., Zhuohua R. (2013) Misunderstanding of the Construction of Academic Style in Colleges and Universities and Its Circumvention Strategy. Journal of Hunan Agricultural University (Social Sciences Edition), 22-24.

[5] LeiLei W. (2011) How to do propaganda work well. Campus, 191.

[6] Dandan T., Yulan H. (2015) Construction and actual effect analysis of the running mode of honesty examination room in colleges and universities. Journal of Jilin Institute of Education, 4-6.

[7] Xiaochun H. (2018) From Core Values to the Realization Path of College Students' Emotional Identity and Behavioral Habits. Journal of Inner Mongolia Normal University, 10-17. 